\title{
Which extratropical cyclones contribute most to the transport of moisture in the southern hemisphere?
}

Article

Accepted Version

Sinclair, V. A. and Dacre, H. F. (2019) Which extratropical cyclones contribute most to the transport of moisture in the southern hemisphere? JGR Atmospheres, 124 (5). pp. 25252545. ISSN 2169-8996 doi:

https://doi.org/10.1029/2018JD028766 Available at https://centaur.reading.ac.uk/82657/

It is advisable to refer to the publisher's version if you intend to cite from the work. See Guidance on citing.

To link to this article DOI: http://dx.doi.org/10.1029/2018JD028766

Publisher: American Geophysical Union

All outputs in CentAUR are protected by Intellectual Property Rights law, including copyright law. Copyright and IPR is retained by the creators or other copyright holders. Terms and conditions for use of this material are defined in the End User Agreement.

www.reading.ac.uk/centaur 
Central Archive at the University of Reading

Reading's research outputs online 


\section{Which extra-tropical cyclones contribute most to the transport of moisture in the Southern Hemisphere?}

V. A. Sinclair, ${ }^{1}$ and H. F. Dacre, ${ }^{2}$

Corresponding author: V. A. Sinclair, Institute for Atmospheric and Earth System Research / Physics, Faculty of Science, University of Helsinki, PO BOX 64, FI-00014, Finland (Victoria.Sinclair@helsinki.fi)

${ }^{1}$ Institute for Atmospheric and Earth

System Research / Physics, Faculty of

Science, University of Helsinki, Helsinki,

Finland

${ }^{2}$ Department of Meteorology, University

of Reading, Reading, UK 
3 Abstract. Predicted changes in Southern Hemisphere (SH) precipitation ${ }_{4}$ and Antarctic ice mass correspond to variations in the meridional moisture ${ }_{5}$ flux (MMF). Thirty-five years of ERA-Interim reanalysis data are combined 6 with an extra-tropical cyclone (ETC) identification and tracking algorithm 7 to investigate factors controlling SH MMF variability in the mid-latitudes s and near Antarctica. ETC characteristics which exert the strongest control 9 on ETC MMF are determined thus identifying which ETCs contribute most

${ }_{10}$ to $\mathrm{SH}$ moisture transport. ETC poleward propagation speed exerts the strongest

${ }_{11}$ control on the ETC MMF across the Antarctic coastline. In SH winter, ETCs

${ }_{12}$ with the largest poleward propagation speeds transport 2.5 times more mois-

${ }_{13}$ ture than an average ETC. In the mid-latitudes, ETC genesis latitude and

${ }_{14}$ poleward propagation speed have a similar influence on ETC MMF. Surpris-

15 ingly, ETC maximum vorticity has little control on ETC MMF. Cyclone com-

${ }_{16}$ positing is used to determine the reasons for these statistical relationships.

${ }_{17}$ ETCs generally exhibit a dipole of poleward and equatorward MMF down-

18 stream and upstream of the cyclone centre respectively. However, ETCs with

19 the largest poleward propagation speeds resemble open frontal waves with

20 strong poleward moisture transport downstream of the cyclone centre only

${ }_{21}$ and thus result in the largest MMF. These results suggest that inhomoge-

${ }_{22}$ neous trends and predicted changes in precipitation over Antarctica may be

${ }_{23}$ due to changes in cyclone track orientation, associated with changes to the

${ }_{24}$ large-scale background flow, in addition to changes in cyclone number or in25 tensity. 


\section{Introduction}

Atmospheric water vapor plays a fundamental role in determining the state of the

${ }_{27}$ Earth's climate. Water vapor is a powerful greenhouse gas and thus its distribution influ-

${ }_{28}$ ences global temperature patterns. Furthermore, the spatial distribution of water vapor,

${ }_{29}$ and in particular the convergence of water vapor, is strongly correlated with precipitation

so patterns. However, water vapor is distributed inhomogeneously across the globe. Typ-

${ }_{31}$ ically the atmospheric moisture content is largest at the equator and near the surface

32 and smallest at the poles and in the upper troposphere due to the Clausius-Clapeyron

${ }_{33}$ equation (which determines the water holding capacity of the atmosphere and predicts an

${ }_{34}$ increase of $7 \%$ for every $1^{\circ} \mathrm{C}$ rise in temperature). However, the atmospheric circulation

35 transports moisture meridionally and vertically resulting in complex spatial patterns and

${ }_{36}$ intrusions of moist air into the mid and high latitudes and mid to upper troposphere.

${ }_{37}$ To identify which aspects of the circulation are most important in the meridional trans-

38 port of moisture, the flow can be decomposed into the mean meridional circulation, sta-

39 tionary eddies and transient eddies. Tietäväinen and Vihma [2008] and Tsukernik and

40 Lynch [2013] applied this traditional flow decomposition method to ERA-40 and ERA-

${ }_{41}$ Interim data respectively. Tietäväinen and Vihma [2008] showed that $85 \%$ of the total

${ }_{42}$ poleward moisture transport at $60^{\circ} \mathrm{S}$ is due to transient eddies, whereas using the newer

${ }_{43}$ reanalysis Tsukernik and Lynch [2013] found that transient eddies were responsible for

${ }_{44} 81 \%$ of the total moisture transport at $60^{\circ} \mathrm{S}$. Transient eddies, deviations from the zonal

${ }_{45}$ and temporal mean, include extra-tropical cyclones (ETCs). Therefore, changes to either

${ }_{46}$ the number or location of ETCs is likely to alter the poleward moisture transport and 
${ }_{47}$ precipitation patterns in the mid and high latitudes. Many studies have considered how

${ }_{48}$ the storm tracks are likely to change in the future in both the northern and southern

${ }_{49}$ hemispheres [e.g. Fyfe, 2003; Wang and Swail, 2006]. However, precipitation patterns

so could also change if the variability of extra-tropical cyclones and the amount of moisture

${ }_{51}$ transported by an ETC changes even if the number of ETCs remains the same.

Changes to moisture transport by ETCs in the Southern Hemisphere (SH) potentially ${ }_{53}$ could have major impacts. The Antarctic ice sheet is the largest potential source of

${ }_{54}$ future sea level rise due to its large mass [Schoen et al., 2015]. Variability in Antarctic ice ${ }_{55}$ mass is determined by the balance between precipitation accumulation over the continent ${ }_{56}$ and mass loss due to melting, sublimation and ice calving [Bromwich, 1990; Davis et al., ${ }_{57}$ 2005; Seo et al., 2015; Roberts et al., 2015]. Since a large fraction of the precipitation in

${ }_{58}$ Antarctica is associated with ETCs, changes in ETC number and moisture transport that ${ }_{59}$ result in a changed distribution of precipitation will be important for future Antarctic ice so mass [Noone et al., 1999; Papritz et al., 2014; Altnau et al., 2015]. There is evidence to ${ }_{61}$ suggest that only a few ETCs are responsible for the majority of the precipitation over ${ }_{62}$ Antarctica, particularly in the interior of the continent [Bromwich, 1988; Krinner et al., 63 1997; Gorodetskaya et al., 2014]. This motivates an investigation of what factors lead to ${ }_{64}$ the greatest variability in the amount of moisture an ETC can transport polewards.

The structure of ETCs has been extensively studied and conceptual cyclone models developed [e.g. Bjerknes and Solberg, 1922; Shapiro and Keyser, 1990]. Carlson [1980] ${ }_{67}$ presented the conveyor belt cyclone model which includes three main air streams: a warm ${ }_{68}$ conveyor belt (WCB), a cold conveyor belt (CCB) and the dry intrusion. The WCB originates in the boundary layer, ascends and moves polewards. Although the conceptual 
70 models have been developed primarily based on northern hemisphere (NH) observations,

71 studies indicate that ETCs in the SH do not differ significantly from those occurring

${ }_{72}$ in the NH. For example, Field and Wood [2007] compared ETCs in the North Atlantic,

${ }_{73}$ North Pacific, South Atlantic and South Pacific using satellite data and concluded that the

${ }_{74}$ cloud and precipitation properties of ETCs with a given strength and water vapor path are

75 similar in all ocean basins. Furthermore, Govekar et al. [2011] created three-dimensional

76 composites of southern hemisphere extra-tropical cyclones using satellite and reanalysis

77 data and concluded that the structure of SH ETCs agrees well with conceptual models

78 with both the warm conveyor belt and dry intrusion being evident in their composites.

The poleward transport of moisture is determined by the water vapor content of the

so atmosphere and the meridional wind velocity. As atmospheric moisture content is largest

${ }_{81}$ at the equator and smallest at the poles, poleward moving airflows, such as the WCB,

82 generally result in a poleward transport of moist air and equatorward moving airflows

${ }_{83}$ (e.g. the CCB and dry intrusion) an equatorward transport of drier air. Within ETCs

${ }_{84}$ the meridional wind velocity is the sum of the meridional velocity of the airflows within

${ }_{85}$ the ETC (ETC-relative airflows) and the meridional velocity of the ETC itself (ETC

${ }_{86}$ propagation velocity). The poleward airflow in ETCs is concentrated in the ascending

${ }_{87}$ moist warm conveyor belt whilst the equatorward airflow occurs in the descending dry

s8 intrusion airflow behind the cold front (Figure 1a). As the warm conveyor belt originates

s9 at lower altitudes and closer to the equator than the dry intrusion, the net ETC-relative

9o meridional moisture flux (MMF) usually contributes a poleward component to the total

${ }_{91}$ MMF associated with ETCs. This suggests that more intense ETCs, with stronger ETC-

${ }_{92}$ relative winds, will transport more moisture polewards than weaker ETCs. The ETC 
${ }_{93}$ propagation velocity on the other hand can result in either a poleward or an equatorward

${ }_{94}$ MMF contribution to the total MMF associated with ETCs depending on their direction

${ }_{95}$ of travel. Thus ETCs with more meridional tracks (large poleward propagation velocity)

96 are likely to transport more moisture polewards than those with more zonal tracks (smaller

${ }_{97}$ poleward propagation velocity, Figure 1b). Finally, ETCs generated at low-latitudes may

${ }_{98}$ transport more moisture polewards than those generated at high-latitudes due to higher

99 atmospheric moisture content at their genesis locations (Figure 1c) and along the tracks

100 that they subsequently follow.

${ }_{101}$ The primary aim of this paper is to identify the synoptic-scale ETCs that contribute the

\section{Data and Method}

D R A F T 
${ }_{115}$ be captured. Pressure level data, with a vertical resolution of $25 \mathrm{hPa}$ between $1000 \mathrm{hPa}$ 
The total vertically integrated meridional moisture flux, $\mathrm{MMF}_{\text {тот }}$, is also calculated from ERA-Interim and is given by

$$
\mathrm{MMF}_{\text {тот }}=-\frac{1}{g} \int_{p 1}^{p 2}(v q) d p
$$

138

\subsection{Masking approach}

To calculate the vertically integrated meridional moisture flux due to ETCs $\left(\mathrm{MMF}_{\mathrm{ETC}}\right)$, the ETC tracks are combined with a masking method. We follow Hawcroft et al. [2012] and assume that the area influenced by an ETC is given by a circle of constant radius centered on the localized cyclonic vorticity maximas identified by TRACK. Thus, an "ETC mask" is calculated for each time step where the regions influenced by an ETC are given a value of one (i.e. they are inside the ETC mask) and regions that are not influenced are given a value of zero (i.e. they are outside the ETC mask). $\mathrm{MMF}_{\mathrm{ETC}}$ is then calculated by

$$
\mathrm{MMF}_{\mathrm{ETC}}=\mathrm{MMF}_{\text {тот }} \times \text { mask } .
$$


velocity. For each variable, six bins were created (see Table 1). However, the tracking and masking approach does have disadvantages, one of which is the assumption that ETCs have a constant radius. Rudeva and Gulev [2007] showed that cyclone radius (calculated to be where the first radial derivative of SLP becomes zero) varies during the cyclone life cycle and can vary from $300 \mathrm{~km}$ over continents to more than $900 \mathrm{~km}$ over oceans. Here we use a constant radius of 12 degrees except in DJF (southern hemisphere summer) when a radius of 11 degrees is used. These values were selected based on previous studies [e.g. Utsumi et al., 2016; Hawcroft et al., 2012; Zappa et al., 2015] and by visually examining composite cyclones. The sensitivity of ETC MMF to the choice of radius was investigated (Figure 2). As expected, increasing the radius from 8 to 12 degrees increases the amount of $\mathrm{MMF}_{\mathrm{ETC}}$. Changing the radius does not alter the latitude of the maximum $\mathrm{MMF}_{\mathrm{ETC}}$ nor how $\mathrm{MMF}_{\mathrm{ETC}}$ varies with latitude. The sensitivity of the results to the choice of radius (R) is considered further in sections 3 and 4 , however, the choice of radius does not affect the main conclusions of this study.

\subsection{Cyclone composite approach}

12 The masking approach has the advantages that all ETCs can be easily included in the analysis and that it is simple to determine the MMF due to ETCs across any given latitude. However, disadvantages of this approach include that all stages of ETCs are considered together (i.e intensification and decay) and that the spatial pattern of MMF relative to the center of a ETC cannot be determined. Thus, to complement the masking approach, a cyclone compositing approach is also taken. We follow the method previously used by Catto et al. [2010] and Dacre et al. [2012] to create cyclone composites of the meridional moisture flux (MMF), total column water vapor (TCWV) and mean sea level 
${ }_{170}$ pressure (MSLP). First, the ETC tracks identified by TRACK that are to be included in ${ }_{171}$ each composite are selected. Following a similar approach to Rudeva and Gulev [2011], ${ }_{172}$ who created cyclone composites for subsets of North Atlantic cyclones based on their 173 intensity and lysis regions, we create composites for each of our bins (Table 1). For each 174 composite 200 individual ETCs are selected from the "top" end of each bin. For example, 175 for the speed bin 0 - 2 degrees per day, all ETCs in this bin are identified and ordered 176 in terms of their speed and the top 200 from this bin (i.e. the fastest moving ETCs) are 177 then selected to create the composite from. Cyclones were selected from the top of each ${ }_{178}$ bin to make sure that the composites had limited variability in terms of the predictor variable. Second, the position of each ETC at different offset times relative to the time

\section{Climatology of Total and ETC Meridional Moisture Flux}


192 tic coastline), the largest values of $\overline{M M F_{T O T}}$ occur in June-July-August (JJA) despite 
${ }_{215}$ of the number of grid points affected by an ETC to the total number of grid points.

${ }_{216}$ For both ratios a radius of 12 degrees was used for JJA and 11 degrees for DJF. We then ${ }_{217}$ compare these two ratios. In JJA at $60^{\circ} \mathrm{S}$, ETCs are responsible for $83 \%$ of the total MMF ${ }_{218}$ (assuming $\mathrm{R}=12$ degrees) while ETCs influence $81 \%$ of grid points at $60^{\circ} \mathrm{S}$ (Figures $3 \mathrm{c}$ ). ${ }_{219}$ In DJF (assuming $\mathrm{R}=11$ degrees), the respective values are $85 \%$ and $75 \%$ (Figures $3 \mathrm{~d}$ ). Thus, ETCs are only responsible for slightly more meridional moisture transport than ${ }_{221}$ what would be expected in a climatological sense. However, if only poleward moving ${ }_{222}$ ETCs are considered, ETCs are responsible for $84 \%$ of the total MMF in JJA yet only ${ }_{223}$ influence $60 \%$ of grid points. In DJF, poleward moving ETCs are responsible for $91 \%$ of ${ }_{224}$ the total MMF but influence only $58 \%$ of grid points. It is thus apparent that equatorward ${ }_{225}$ moving ETCs contribute negatively to the net ETC-related MMF in DJF, and contribute ${ }_{226}$ very little to the net ETC-related MMF in JJA. If only ETCs which move polewards ${ }_{227}$ between the time of genesis and time of maximum intensity are considered, as is the case ${ }_{228}$ in the remainder of this paper, then it can be concluded that ETCs contribute more to the net poleward moisture transport than would be expected based on the ratio of the area affected by an ETC to the total area.

\section{Characteristics of ETCs}

Is it just the number of ETCs that control the $\overline{M M F_{E T C}}$ or do the characteristics of individual ETCs play a role in determining how much moisture is transported polewards in the southern hemisphere? To answer this question we normalized the sum of $M M F_{E T C}$ at each grid point calculated over all time steps in each season by the sum of the mask counts at each grid point (i.e. the number of times a grid point has been affected by a 
ETC),

$$
\left|M M F_{E T C}\right|=\frac{\sum M M F_{E T C}}{\# \text { masks }}
$$

${ }_{231}$ to obtain $\left|M M F_{E T C}\right|$ where the vertical bars denote the average MMF per ETC. The 232 zonal mean of this quantity is represented by $\overline{\left|M M F_{E T C}\right|}$. We now focus only on two ${ }_{233}$ seasons: JJA and DJF.

\subsection{ETC Genesis Latitude}

${ }^{234}$ Figure 4 shows how $\overline{\left|M M F_{E T C}\right|}$ varies with ETC genesis latitude in both JJA and DJF ${ }_{235}$ in the mid-latitudes $\left(50^{\circ} \mathrm{S}\right.$, Figure $\left.4 \mathrm{a}\right)$ and near the Antarctic coastline $\left(65^{\circ} \mathrm{S}\right.$, Figure $\left.4 \mathrm{~b}\right)$. ${ }_{236}$ In JJA at both $50^{\circ}$ and $65^{\circ} \mathrm{S}$ there are large regression (Table 2 ) and correlation coefficients ${ }_{237}$ (Table $\mathrm{T} 1$ in supporting material) significant at the $99 \%$ level, indicating strong linear ${ }_{238}$ relationships between 90 - genesis latitude (i.e. distance from the pole) and $\overline{\left|M M F_{E T C}\right|}$. 
${ }^{251}$ average whilst red colors indicate that they have larger $\left|M M F_{E T C}\right|$ than average. Average ${ }_{252}\left|M M F_{E T C}\right|$ is due to all poleward traveling cyclones at each grid point (i.e. those ETCs

${ }_{253}$ which moved equatorward between the time of genesis and time of maximum intensity were

${ }^{254}$ excluded). In general $\left|M M F_{E T C}\right|$ is greater for ETCs generated at lower latitudes but the ${ }_{255}$ relationship between $\left|M M F_{E T C}\right|$ and ETC genesis latitude is not zonally homogeneous ${ }_{256}$ and varies between seasons (Figures $5 \mathrm{a}-\mathrm{c}, 6 \mathrm{a}-\mathrm{c}$ ). In JJA and DJF there is a strong ${ }_{257}$ relationship between genesis latitude and $\left|M M F_{E T C}\right|$ in Pacific sector between $140^{\circ} \mathrm{W}$ ${ }_{258}$ and $60^{\circ} \mathrm{W}$, which is shifted poleward in JJA compared to in DJF. A strong relationship ${ }_{259}$ is also present in the Indian Ocean between $90^{\circ} \mathrm{E}$ and $120^{\circ} \mathrm{E}$ in JJA and slightly more to ${ }_{260}$ the west in DJF - between $60^{\circ} \mathrm{E}$ and $90^{\circ} \mathrm{E}$. In particular, ETCs generated north of $45^{\circ} \mathrm{S}$ ${ }_{261}$ (Figure 5c, 6c) appear important for transporting moisture onto the coastal areas of East ${ }_{262}$ Antarctic. This is consistent with Lagrangian back trajectory studies which show that ${ }_{263}$ Antarctic precipitation is dominated by moisture from a subtropical/mid-latitude band ${ }^{264}$ [Delaygue et al., 2000; Sodemann and Stohl, 2009]. In contrast, in the Ross Sea and in the ${ }_{265}$ Weddell Sea there is little relationship between genesis latitude and $\left|M M F_{E T C}\right|$ in either 266 JJA or DJF.

\subsection{ETC Relative Vorticity}


due to fast moving ETCs may be dominated by the moisture evaporated at the ETC genesis location whereas slower moving ETCs likely depend more on moisture acquired along their track which will be less than that available at their more equatorward genesis locations. As a result, fast moving ETCs have a much larger poleward MMF than slow moving ETCs.

The strong relationship between poleward propagation speed and MMF is fairly spatially homogeneous (Figure $5 \mathrm{~g}-\mathrm{i}$ ) in JJA suggesting that the ETC poleward propagation speed is universally important for determining $\left|M M F_{E T C}\right|$. In DJF, there is more spatial variability, with the strongest relationship observed in the south Atlantic. ETCs with large poleward propagation speeds typically results in 2.5 (i.e. $\log _{10}(2.5)=0.39$ ) times the average $\left|M M F_{E T C}\right|$. The $\mathrm{SH}$ extra-tropical storm track is more asymmetric in winter (JJA) than in summer (DJF), with a spiral from the Atlantic and Indian Oceans towards Antarctica [Hoskins and Hodges, 2005]. This is confirmed when the mean poleward propagation speed of poleward moving ETCs is considered. In JJA, poleward moving ETCs have a mean poleward propagation speed of 3.87 degrees latitude by day whereas in DJF the mean value is 3.46 degrees per day. Normalized histograms (not shown) also demonstrate that a larger percentage of ETCs in JJA have large poleward propagation speeds than in DJF: 8.3\% of ETCs have a poleward propagation speed greater than 8 degrees per day in JJA but only $5.3 \%$ do in DJF. This seasonal change in track orientation is thus very important for determining the seasonal differences in poleward MMF and precipitation in high latitudes and over the Antarctic continent. 


\subsection{Multiple linear regression}

The results shown in Figure 4 and Table 2 are based on three independent linear regressions which were conducted between $\overline{\left|M M F_{E T C}\right|}$ and each predictor variable (maximum cyclonic vorticity, poleward propagation speed and 90-genesis latitude). Weak but statistically significant linear relations exist between the different predictor variables. Therefore, to determine if the interaction between the predictors significantly affects the linear relationships shown in Figure 4, multiple linear regression between the three predictors and $\overline{\left|M M F_{E T C}\right|}$ at $50^{\circ} \mathrm{S}$ and $65^{\circ} \mathrm{S}$ is performed.

Rather than dividing the data into bins and thus having a sample size of 6 as was the case for the simple linear regression, here each time step is considered as one sample resulting in a sample size of 12280 for JJA and 12636 for DJF. First, for each time step all ETCs which could contribute to $\mathrm{MMF}_{\mathrm{ETC}}$ at either $50^{\circ} \mathrm{S}$ or $65^{\circ} \mathrm{S}$ are identified. In JJA, as the radius of the ETC mask is 12 degrees, this is all ETCs with their center located between $38^{\circ} \mathrm{S}$ and $62^{\circ} \mathrm{S}$ for $\mathrm{MMF}_{\mathrm{ETC}}$ at $50^{\circ} \mathrm{S}$ and between $53^{\circ} \mathrm{S}$ and $77^{\circ} \mathrm{S}$ for $\mathrm{MMF}_{\mathrm{ETC}}$ at $65^{\circ} \mathrm{S}$. In DJF, since the radius is 11 degrees, for $\mathrm{MMF}_{\mathrm{ETC}}$ at $50^{\circ} \mathrm{S}$ this is all ETCs with their center between $39^{\circ} \mathrm{S}$ and $61^{\circ} \mathrm{S}$ and between $54^{\circ} \mathrm{S}$ and $76^{\circ} \mathrm{S}$ for $\mathrm{MMF}_{\text {ЕтC }}$ at $65^{\circ} \mathrm{S}$. The maximum cyclonic vorticity, mean poleward propagation speed between the time of genesis and time of maximum intensity, and the genesis latitude were obtained for each of these ETCs. So that ETCs closer to the latitude of interest (i.e. $50^{\circ} \mathrm{S}$ or $65^{\circ} \mathrm{S}$ ) are more strongly weighted than those further away, the predictor values were weighted by the ratio of the length of the chord of the ETC mask which lies along the relevant latitude circle to the maximum ETC mask diameter (22 or 24 degrees). Thus, the weighted predictor 
values $\left(P_{\text {weighted }}\right)$ are given by

$$
\mathrm{P}_{\text {weighted }}=P \times \frac{2 \sqrt{\left(R^{2}-a^{2}\right)}}{2 R}
$$

346

347 
${ }_{367}$ imum vorticity and genesis latitude has a significant regression coefficient demonstrating

\section{Cyclone Composites}

384 hence the cyclones are located at a range of latitudes.

385 
${ }_{389}$ ETCs which have their genesis latitudes equatorward of $35^{\circ} \mathrm{S}$ have weak horizontal pressure gradients and symmetrical MSLP patterns, yet large values of poleward MMF in JJA (Figure 7c) and even more so in DJF (Figure 8c). In JJA, the TCWV values downstream and equatorward of the ETC center exceed $30 \mathrm{~kg} \mathrm{~m}^{-2}$, and $50 \mathrm{~kg} \mathrm{~m}^{-2}$ in DJF, demonstrating that the large poleward MMF is primarily due to large values of 394 local moisture rather than strong meridional system relative winds. In both JJA and DJF, ETCs with genesis latitudes in the mid-latitudes (Figures 7b and 8b) have stronger 396 MSLP gradients and thus stronger system relative meridional winds than ETCs with ${ }_{397}$ genesis regions closer to the equator (composites of 900-hPa wind speed are shown in ${ }_{398}$ Figures S2 and S3 of the supporting material). However, the MMF is still reduced as 399 the TCWV is much lower which indicates that the availability of moisture still dominates ${ }_{400}$ the MMF pattern. For ETCs with genesis latitudes close to the poles, the MSLP pattern ${ }_{401}$ indicates a more zonal flow which combined with the very low values of TCWV in these 402 regions leads to weak MMF (Figures 7a and 8a).

In JJA and DJF, the ETC composites with the strongest maximum vorticity (Figures ${ }_{404} 7 \mathrm{f}$ and $8 \mathrm{f}$ ) have strong MSLP gradients downstream of the ETC center co-located with ${ }_{405}$ high values of TCWV. In comparison to the composite ETCs with the most equatorward ${ }_{406}$ genesis regions (Figures $7 \mathrm{c}$ and $8 \mathrm{c}$ ) or the fastest propagation speeds (Figures $7 \mathrm{i}$ and $8 \mathrm{i}$ ), 
${ }_{412}$ MMF in the weakest ETC composite is due to weaker MSLP gradients and weaker system ${ }_{413}$ relative winds (see Figures S1 and S2).

${ }_{414}$ ETCs which move the fastest (Figures $7 \mathrm{i}$ and $8 \mathrm{i}$ ) have a different MSLP and TCWV ${ }_{415}$ structure compare to the other "top" bins (Figures 7a,d and 8a,d). In both JJA and DJF, ${ }_{416}$ the fastest moving ETC composites do not have a closed low associated with them. Instead, these ETCs resemble frontal waves and have large values of poleward MMF over a ${ }_{418}$ meridionally extensive but zonally narrow area. Furthermore, the ETCs with the fastest ${ }_{419}$ poleward propagation speed do not have any equatorward MMF on the upstream side ${ }_{420}$ of the cyclone. In contrast, the slowest moving ETCs have closed low pressure centers ${ }_{421}$ and broader areas of high TCWV. However, the large values of MMF associated with the ${ }_{422}$ fastest moving ETCs are likely enhanced by the large-scale, low-frequency flow that these ${ }_{423}$ ETCs may be embedded in. Binder et al. [2017] analyzed an ETC which lead to extreme ${ }_{424}$ poleward heat transport and concluded one reason for this was the superposition of ETCs ${ }_{425}$ (synoptic-scale variability) and a stationary anticyclone (low-frequency variability). Sim${ }_{426}$ ilarly, in an idealized study Tamarin and Kaspi [2017] show that the poleward deflection ${ }_{427}$ of the ETCs can be affected by stationary waves and thus low-frequency variability likely ${ }_{428}$ affects the poleward propagation speed of ETCs. However, an in-depth analysis of the ${ }_{429}$ low-frequency flow contribution to the poleward movement of ETCs and their MMF is ${ }_{430}$ beyond the scope of the current study.

${ }_{431}$ The composites are only shown 24 hours before the time of maximum intensity, however, ${ }_{432}$ the time dependence of the composite spatial mean TCWV and MMF are shown in Figure ${ }_{433} 9$ for JJA and Figure 10 for DJF. For each bin and offset time (i.e. each composite), the 
${ }_{434}$ spatial mean TCWV and MMF, weighted by grid area, is calculated over the circular 11

(DJF) or 12 (JJA) degree radius cap centered on each composite.

In JJA and DJF, TCWV and MMF are largest for ETCs with genesis latitudes closest to the equator at all offset times. Statistically significant positive linear relationships between mean TCWV and genesis latitude and mean MMF and genesis latitude are present at all offset times (Table 4) demonstrating that the relationship found between genesis latitude and MMF in section 4 is valid throughout the ETC life cycle. For all genesis latitude bins, TCWV and MMF decrease in a similar manner with increasing offset time which strongly indicates that the relationship between genesis latitude and MMF is primarily driven by moisture availability. However, TCWV has a maximum value at -48 hrs whereas MMF peaks at -24 hrs which suggests that in the developing part of the life cycle, the system relative winds or system speed can play a secondary role in determining the MMF.

In comparison to the genesis latitude bins, the variation of mean TCWV with maximum vorticity is small at all offset times in both JJA (Figure 9c) and DJF (Figure 10c). TCWV decreases with increasing offset time for all bins but the rate of decrease is greater for stronger ETCs: at -48 and -24 hrs, TCWV is higher in the strongest ETCs but at later offset times, TCWV is higher for weaker ETCs. Consequently, in JJA, there is no statistically significant relationship between TCWV and maximum vorticity at $-48,-24$ or “52 0 hours but at both 24 and 48 hours, there is a statistically significant negative correlation ${ }_{53}$ (Table 4). Similarly in DJF, a significant positive linear relationship exists at -48 hours and statistically significant negative relationships occur at 0,24 and 48 hours. Despite the lack of significant positive relationship between TCWV and maximum vorticity, the mean MMF does increase with maximum vorticity in the early stages of the ETC life cycle. 
${ }_{457}$ Positive statistically significant linear relationships exists between MMF and maximum ${ }_{458}$ vorticity $-48,-24$ and +48 hours in JJA and at $-48,-24$ and 0 hours in DJF. Thus, it can

${ }_{459}$ be concluded that the positive correlation between MMF and maximum vorticity must ${ }_{460}$ be primarily due to variations in the meridional wind field. Given that the positive linear ${ }_{461}$ regression between maximum vorticity and MMF is only present during the intensification part of the ETC life cycle it is likely that the masking method, which includes all stages of ${ }_{463}$ the ETC simultaneously, will underestimate the correlation between maximum intensity ${ }_{464}$ and MMF.

${ }_{465}$ The mean TCWV of the ETC composites with different speeds also decreases with ${ }_{466}$ increasing offset time for both JJA and DJF (figures 9e, 10e). The fastest moving ETCs ${ }_{467}$ experience a more rapid decrease in TCWV than the slowest moving ETCs as the fastest ${ }_{468}$ ETCs rapidly travel to higher latitudes where climatologically the TCWV is lower. This ${ }_{469}$ results in negative statistically significant linear relationships between speed and TCWV ${ }_{470}$ at $0,+24$ and +48 hours in both DJF and JJA (Table 4 ). At -48 and -24 hrs, there are ${ }_{471}$ weak positive or negative correlations between TCWV and speed in JJA, but despite this ${ }_{472}$ MMF increases greatly with increasing speed and strong significant positive correlations 473 are evident between MMF and ETC speed in both DJF and JJA. This demonstrates that ${ }_{474}$ before the ETCs reach their maximum intensity the correlation between MMF and speed ${ }_{475}$ is not driven by moisture availability and consequently must be due to either system 476 relative winds (as suggested by Figures 7i and 8i) or the system propagation speed (which ${ }_{477}$ may be influenced by low-frequency variability and stationary waves) or a combination ${ }_{478}$ of both. MMF peaks at -24 hours for all speed bins in both JJA and DJF and decreases ${ }_{479}$ after this. As was the case with TCWV, the MMF decreases faster with offset time for 
${ }_{480}$ the fastest moving ETCs than for the slowest moving ETCs (figures 9f, 10f). After the time of maximum intensity negative correlations exist between speed and both TCWV

${ }_{482}$ and MMF indicating that the correlation between MMF and speed is driven by moisture 483 availability.

\section{Discussion and Conclusions}

${ }_{484}$ We investigate meridional moisture transport by synoptic-scale, extra-tropical cyclones ${ }_{485}$ in the Southern Hemisphere in all seasons but with more in depth analysis performed ${ }_{486}$ for summer (DJF) and winter (JJA). We identify and track Southern Hemisphere extra${ }_{487}$ tropical cyclones (ETCs) in ERA-Interim reanalysis data and calculate the vertically ${ }_{488}$ integrated meridional moisture flux (MMF) associated with ETCs.

${ }_{489}$ We determine which ETC characteristics exert the strongest control on the amount of moisture transported polewards per cyclone. In $\mathrm{SH}$ winter, at $50^{\circ} \mathrm{S}$, the ETC genesis

${ }_{491}$ latitude is most important in determining the poleward moisture flux, closely followed ${ }_{492}$ by the ETC poleward propagation speed whereas ETC maximum vorticity only exerts ${ }_{493}$ a weak control on the MMF. Near the Antarctic coastline, at $65^{\circ} \mathrm{S}$, the most influential ${ }_{494}$ ETC characteristic is the ETC poleward propagation speed and again ETC maximum 495 relative vorticity is found to be the least influential ETC characteristic. These results ${ }_{496}$ were not sensitive to the choice of ETC radius. In SH summer very similar results are ${ }_{497}$ found at $50^{\circ} \mathrm{S}$ as in winter and at $65^{\circ} \mathrm{S}$ ETC poleward propagation speed remains the 
We thus conclude that ETC poleward propagation speed has the strongest influence on ETC MMF, particularly at high latitudes, and that ETCs which travel quickly from low to high-latitudes are responsible for considerably more MMF to Antarctica than those which travel poleward slowly. This is likely because the moisture moves with the ETC as it travels polewards and is subject to less dilution and cycling. However, the poleward MMF of the fastest moving ETCs may be enhanced by transport by the low frequency background flow in which the ETCs is embedded within. This result suggests that if ETC tracks become more meridional in the future and hence if ETCs move poleward faster then the MMF due to ETCs would increase. Tamarin-Brodsky and Kaspi [2017] applied TRACK to CMIP5 models and showed that there is an increase in the latitudinal displacement of storms under global warming in all storm track regions (their Figure 3). Furthermore, Uotila et al. [2013] showed that the track orientation of ETCs near the Antarctic coastline become more meridional when the Southern Annular Mode (SAM) is positive and Marshall [2003] showed the SAM has exhibited a positive trend in recent years. Combined with our results, which indicate that cyclones with more meridional tracks transport more moisture, these earlier results could imply that in the future, poleward moisture transport, and in particular moisture transport to Antarctic may increase.

Our results also show that in the mid-latitudes genesis latitude exerts a strong control on $\mathrm{MMF}_{\mathrm{ETC}}$ which means that if ETC genesis regions move polewards, then the $\mathrm{MMF}_{\mathrm{ETC}}$ would decrease. However, in DJF the correlation between genesis latitude and ETC MMF decreases towards the pole, indicating that the MMF associated with a ETC near the Antarctic coastline is only weakly influenced by the environment in which it forms. This in turn suggests that by the time the ETC reaches Antarctica, the original sub-tropical 


\section{References}


Delaygue, G., V. Masson, J. Jouzel, R. D. Koster, and R. J. Healy (2000), The origin of Antarctic precipitation: a modelling approach, Tellus B, 52(1).

Field, P. R., and R. Wood (2007), Precipitation and cloud structure in midlatitude cyclones, J. Climate, 20(2), 233-254.

Frieler, K., P. U. Clark, F. He, C. Buizert, R. Reese, S. R. Ligtenberg, M. R. van den Broeke, R. Winkelmann, and A. Levermann (2015), Consistent evidence of increasing Antarctic accumulation with warming, Nature Climate Change.

Fyfe, J. C. (2003), Extratropical Southern Hemisphere cyclones: harbingers of climate change?, J. Climate, 16, 2802-2805.

Geng, Q., and M. Sugi (2003), Possible change of extratropical cyclone activity due to enhanced greenhouse gases and sulfate aerosols-study with a high-resolution AGCM, J. Climate, 16(13), 2262-2274.

Gorodetskaya, I. V., M. Tsukernik, K. Claes, M. F. Ralph, W. D. Neff, and N. P. M. Van Lipzig (2014), The role of atmospheric rivers in anomalous snow accumulation in East Antarctica, Geophys. Res. Lett., 41, 6199-6206, doi:10.1002/2014GL060881.

Govekar, P. D., C. Jakob, M. J. Reeder, and J. Haynes (2011), The three-dimensional distribution of clouds around southern hemisphere extratropical cyclones, Geophys. Res. Lett., $38(21)$.

Hawcroft, M. K., L. C. Shaffrey, K. I. Hodges, and H. F. Dacre (2012), How much Northern Hemisphere precipitation is associated with extratropical cyclones?, Geophys. Res. Lett., $39(24)$

Hodges, K. I. (1994), A general method for tracking analysis and its application to meteorological data, Mon. Wea. Rev., 122, 2573-2586. 
Hodges, K. I. (1995), Feature tracking on the unit-sphere, Mon. Wea. Rev., 123(12), $3458-3465$.

Hoskins, B. J., and K. I. Hodges (2005), A new perspective on Southern Hemisphere storm tracks, J. Climate, 18(20), 4108-4129.

Jung, T., M. J. Miller, T. N. Palmer, P. Towers, N. Wedi, D. Achuthavarier, J. M. Adams, E. L. Altshuler, B. A. Cash, J. L. Kinter Iii, et al. (2012), High-resolution global climate simulations with the ECMWF model in Project Athena: Experimental design, model climate, and seasonal forecast skill, J. Climate, 25(9), 3155-3172.

Krinner, G., C. Genthon, Z.-X. Li, and P. Le Van (1997), Studies of the Antarctic climate with a stretched-grid general circulation model, J. Geophys. Res., 102(D12), 13,73113,745 .

Lambert, S. J., and J. C. Fyfe (2006), Changes in winter cyclone frequencies and strengths simulated in enhanced greenhouse warming experiments: results from the models participating in the IPCC diagnostic exercise, Climate Dynamics, 26(7-8), 713-728.

Marshall, G. (2003), Trends in the Southern Annular Mode from observations and reanalyses, J. Climate, 16, 4134-4143.

Noone, D., J. Turner, and R. Mulvaney (1999), Atmospheric signals and characteristics of accumulation in Dronning Maud Land, Antarctica, J. Geophys. Res., 104, 19,191$19,211$.

Orr, A., T. Phillips, S. Webster, A. Elvidge, M. Weeks, S. Hosking, and J. Turner (2014), Met Office Unified Model high-resolution simulations of a strong wind event in Antarctica, Q. J. R. Meteorol. Soc., 140, 2287-2297. 
Papritz, L., S. Pfahl, I. Rudeva, I. Simmonds, H. Sodemann, and H. Wernli (2014), The role of extratropical cyclones and fronts for Southern Ocean freshwater fluxes, $J$. Climate, 27(16), 6205-6224.

Parish, T. R., and D. H. Bromwich (1998), A case study of Antarctic katabatic wind interaction with large-scale forcing, Mon. Wea. Rev., 126, 119-209.

Pezza, A. B., and T. Ambrizzi (2003), Variability of Southern Hemisphere cyclone and anticyclone behavior: Further analysis, J. Climate, 16(7), 1075-1083.

Pfahl, S., E. Madonna, M. Boettcher, H. Joos, and H. Wernli (2014), Warm conveyor belts in the era-interim dataset (1979-2010). part ii: Moisture origin and relevance for precipitation, J. Climate, 27(1), 27-40.

Roberts, J., C. Plummer, T. Vance, T. van Ommen, A. Moy, S. Poynter, A. Treverrow, M. Curran, and S. George (2015), A 2000-year annual record of snow accumulation rates for Law Dome, East Antarctica, Climate of the Past, 11(5), 697-707.

Rudeva, I., and S. K. Gulev (2007), Climatology of cyclone size characteristics and their changes during the cyclone life cycle, Mon. Wea. Rev., 135(7), 2568-2587.

Rudeva, I., and S. K. Gulev (2011), Composite analysis of North Atlantic extratropical cyclones in NCEP-NCAR reanalysis data, Mon. Wea. Rev., 139(5), 1419-1446.

Schoen, N., A. Zammit-Mangion, J. C. Rougier, T. Flament, F. Rémy, S. Luthcke, and J. L. Bamber (2015), Simultaneous solution for mass trends on the West Antarctic Ice Sheet, The Cryosphere, 9(2), 805-819.

Seo, K.-W., C. R. Wilson, T. Scambos, B.-M. Kim, D. E. Waliser, B. Tian, B.-H. Kim, and J. Eom (2015), Surface mass balance contributions to acceleration of Antarctic ice mass loss during 2003-2013, J. Geophys. Res. 
Shapiro, M. A., and D. Keyser (1990), Extratropical Cyclones: The Erik Palmén Memorial Volume, chap. Fronts, jet streams and the tropopause, pp. 167-191, Amer. Meteor. Soc. Sinclair, V. A., and H. F. Dacre (2019), Southern Hemisphere cyclones tracks 1979-2013, doi:10.5281/zenodo.2559459.

Sodemann, H., and A. Stohl (2009), Asymmetries in the moisture origin of Antarctic precipitation, Geophys. Res. Lett., 36(22).

Tamarin, T., and Y. Kaspi (2017), Mechanisms controlling the downstream poleward deflection of midlatitude storm tracks, J. Atmos. Sci., $74(2), 553-572$.

Tamarin-Brodsky, T., and Y. Kaspi (2017), Enhanced poleward propagation of storms under climate change, Nature Geoscience, 10(12), 908.

Tietäväinen, H., and T. Vihma (2008), Atmospheric moisture budget over Antarctica and the Southern Ocean based on the ERA-40 reanalysis, Int. J. Climatol., 28, 1977-1995.

Trenberth, K. E., A. Dai, R. M. Rasmussen, and D. B. Parsons (2003), The changing character of precipitation, Bull. Amer. Meteor. Soc., 84(9), 1205-1217.

Tsukernik, M., and A. H. Lynch (2013), Atmospheric meridional moisture flux over the Southern Ocean: a story of the Amundsen Sea, J. Climate, 26, 8055-8064.

Uotila, P., T. Vihma, and M. Tsukernik (2013), Close interactions between the antarctic cyclone budget and large-scale atmospheric circulation, Geophys. Res. Lett., 40(12), $3237-3241$.

Utsumi, N., H. Kim, S. Kanae, and T. Oki (2016), Relative contributions of weather systems to mean and extreme global precipitation, Journal of Geophysical Research: Atmospheres, 122(1), 152-167, doi:10.1002/2016JD025222. 
${ }_{705}$ Wang, X. L., and F. W. Swail, V. R. amd Zwiers (2006), Climatology and changes of extratropical cyclone activity: Comparison of ERA-40 with NCEP-NCAR reanalysis for 19582001, J. Climate, 19, 3145-3166. Spiral Jet, J. Atmos. Sci., 64, 548563.

Zappa, G., L. C. Shaffrey, and K. I. Hodges (2013), The ability of CMIP5 models to 711 simulate North Atlantic extratropical cyclones, J. Climate, 26(15), 5379-5396. Zappa, G., M. K. Hawcroft, L. Shaffrey, E. Black, and D. J. Brayshaw (2015), Extrat${ }_{713}$ ropical cyclones and the projected decline of winter Mediterranean precipitation in the CMIP5 models, Climate Dynamics, 45(7-8), 1727-1738. 
(a) ETC-relative Airflows

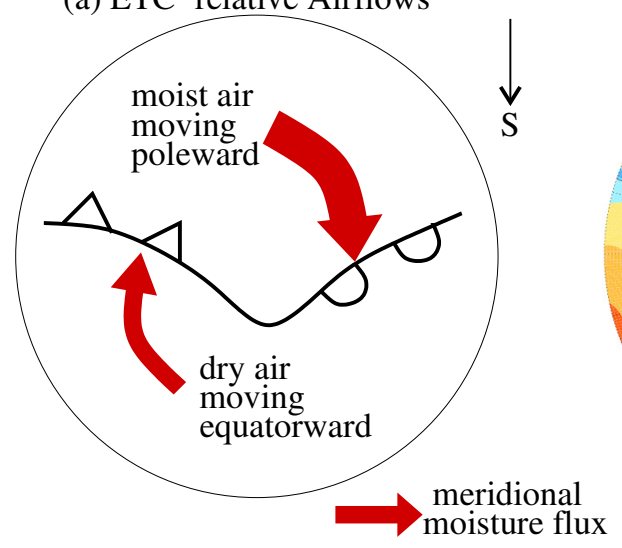

(b) ETC Track Orientation

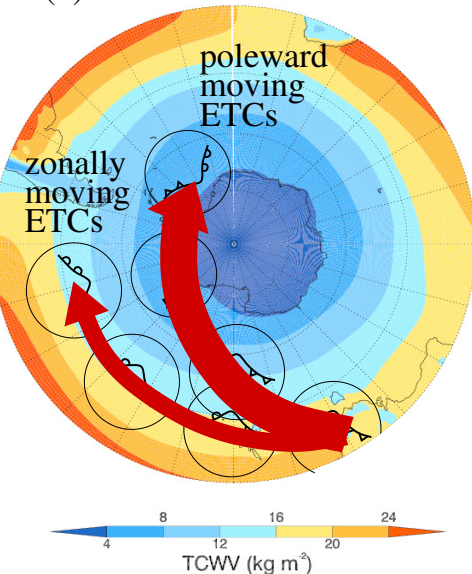

(c) ETC Genesis Latitude

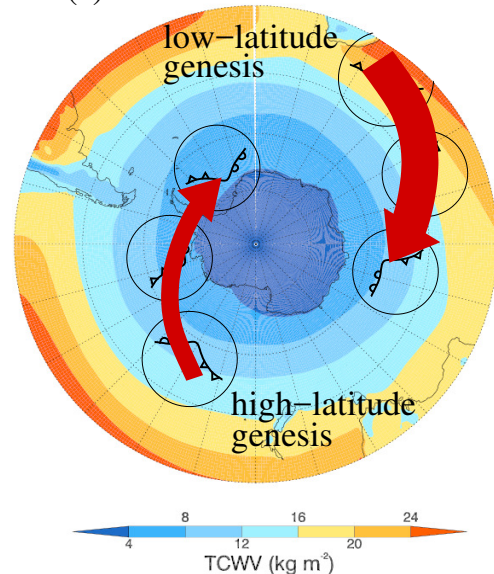

Figure 1. Schematic demonstrating the MMF associated with (a) ETC-relative airflows, (b) ETC track orientations and (c) ETC genesis latitudes. (b) and (c) overlaid on 1979-2014 annual mean total column water vapor (TCWV). The width of the arrows indicate the relative magnitude of the MMF. 

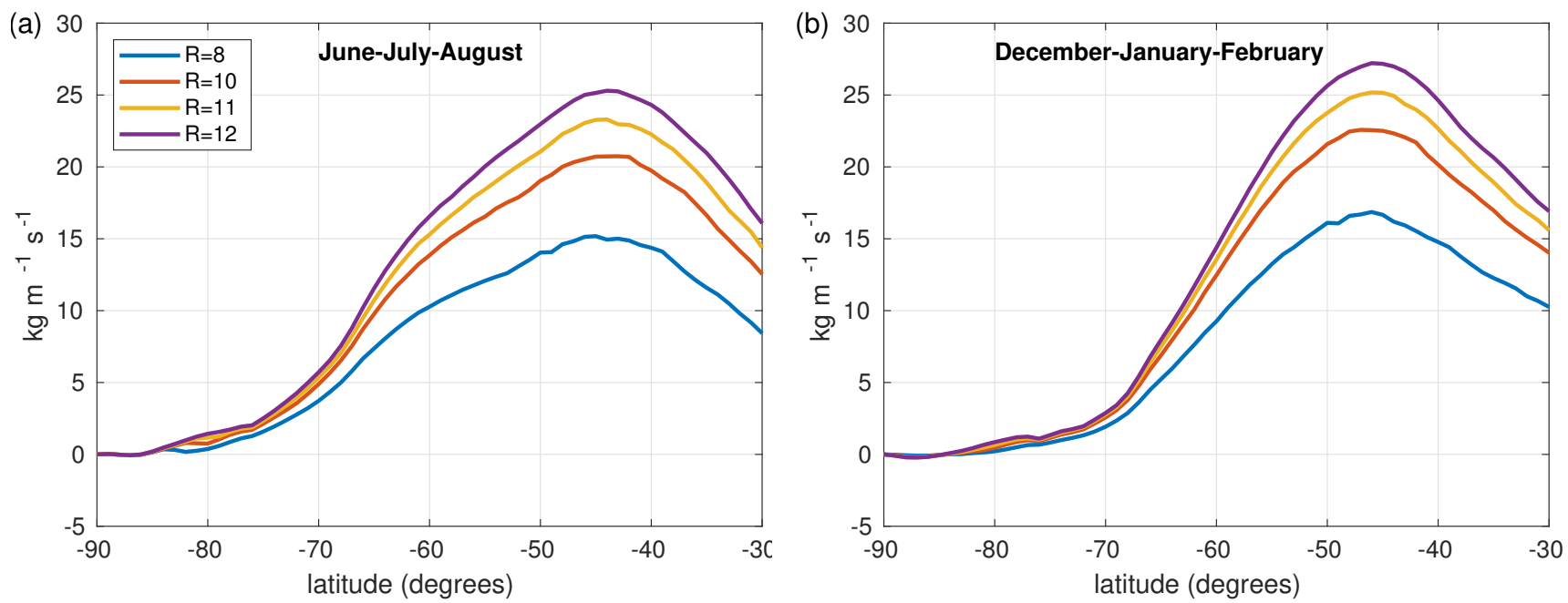

Figure 2. Sensitivity of the annual and zonal mean (calculated over 35 years of ERA-Interim data) net ETC-related meridional moisture flux due to the definition of the ETC radius for (a) JJA and (b) DJF. Blue lines show an ETC radius of 8 degrees, orange lines 10 degrees, yellow lines 11 degrees, and purple lines 12 degrees.

Table 1. Bins used to determine the effect of maximum vorticity, the genesis latitude and the poleward propagation velocity of ETCs on the ETC-related meridional moisture transport. The divisions between the bins were determined by first analyzing probability density functions (PDFs) of each predictor variable.

\begin{tabular}{cccc}
\hline Bin & $\begin{array}{c}\text { Max vorticity } \\
\left(\mathrm{s}^{-1}\right)\end{array}$ & $\begin{array}{c}\text { Genesis Latitude } \\
\left({ }^{\circ} \mathrm{S}\right)\end{array}$ & $\begin{array}{c}\text { Poleward Velocity } \\
(\text { degrees per day })\end{array}$ \\
\hline 1 & $1.0-5.0 \times 10^{-5}$ & $>67.5$ & $0-2$ \\
2 & $5.0-6.5 \times 10^{-5}$ & $62.5-67.5$ & $2-4$ \\
3 & $6.5-8.0 \times 10^{-5}$ & $55.0-62.5$ & $4-6$ \\
4 & $8.0-9.5 \times 10^{-5}$ & $45.0-55.0$ & $6-8$ \\
5 & $9.5-10.5 \times 10^{-5}$ & $35.0-45.0$ & $8-10$ \\
6 & $>10.5 \times 10^{-5}$ & $<35.0$ & $>10$ \\
\hline
\end{tabular}


Table 2. Regression coefficients for simple linear regression conducted between the standardized predictors and the zonally averaged ETC-related MMF per ETC mask, $\overline{\left|M M F_{E T C}\right|}$ at different latitudes in JJA and DJF. Predictors are centered on their mean values and normalized by their standard deviation. Values in bold are statistically significant at the $99 \%$ level. Italic values are statistically significant at the $95 \%$ level.

\begin{tabular}{c|cccccc}
\hline latitude & $\begin{array}{c}\text { genesis lat } \\
\text { JJA }\end{array}$ & $\begin{array}{c}\text { genesis lat } \\
\text { DJF }\end{array}$ & $\begin{array}{c}\text { vorticity } \\
\text { JJA }\end{array}$ & $\begin{array}{c}\text { vorticity } \\
\text { DJF }\end{array}$ & $\begin{array}{c}\text { speed } \\
\text { JJA }\end{array}$ & $\begin{array}{c}\text { speed } \\
\text { DJF }\end{array}$ \\
\hline $40^{\circ} \mathrm{S}$ & $\mathbf{3 4 . 7 2}$ & $\mathbf{3 6 . 0 3}$ & 0.92 & 14.26 & $\mathbf{3 7 . 7 9}$ & $\mathbf{4 6 . 0 2}$ \\
$45^{\circ} \mathrm{S}$ & $\mathbf{3 5 . 4 3}$ & $\mathbf{4 3 . 8 4}$ & 0.44 & 9.56 & $\mathbf{3 4 . 5 2}$ & $\mathbf{4 5 . 2 2}$ \\
$50^{\circ} \mathrm{S}$ & $\mathbf{3 0 . 5 4}$ & $\mathbf{3 9 . 8 0}$ & 0.96 & 4.31 & $\mathbf{2 7 . 5 4}$ & $\mathbf{3 7 . 9 9}$ \\
$55^{\circ} \mathrm{S}$ & $\mathbf{2 4 . 2 9}$ & 26.61 & $\mathbf{2 . 8 8}$ & $\mathbf{1 . 8 4}$ & $\mathbf{1 9 . 1 2}$ & $\mathbf{2 7 . 3 4}$ \\
$60^{\circ} \mathrm{S}$ & $\mathbf{1 4 . 4 0}$ & 10.35 & $\mathbf{3 . 0 2}$ & -0.11 & $\mathbf{1 2 . 8 0}$ & $\mathbf{1 8 . 4 1}$ \\
$65^{\circ} \mathrm{S}$ & $\mathbf{7 . 2 8}$ & 2.65 & $\mathbf{2 . 2 1}$ & -1.03 & $\mathbf{7 . 8 6}$ & $\mathbf{1 0 . 9 6}$ \\
$70^{\circ} \mathrm{S}$ & $\mathbf{2 . 9 7}$ & 0.54 & 1.28 & -0.33 & $\mathbf{3 . 9 2}$ & $\mathbf{4 . 6 9}$ \\
$75^{\circ} \mathrm{S}$ & $\mathbf{1 . 6 5}$ & 0.54 & 1.07 & 0.74 & $\mathbf{1 . 9 9}$ & 1.85 \\
\hline
\end{tabular}

Table 3. Regression coefficients for multiple linear regression conducted between the standardize predictors and the zonally averaged ETC-related MMF per ETC mask, $\overline{\left|M M F_{E T C}\right|}$ at different latitudes in JJA and DJF. Predictors are centered on their mean values and normalized by their standard deviation. Values in bold are statistically significant at the $99 \%$ level. Italic values are statistically significant at the $95 \%$ level.

\begin{tabular}{lcc|cc}
\hline Season & \multicolumn{2}{c}{ JJA } & \multicolumn{2}{c}{ DJF } \\
\hline Latitude & $50^{\circ} \mathrm{S}$ & $65^{\circ} \mathrm{S}$ & $50^{\circ} \mathrm{S}$ & $65^{\circ} \mathrm{S}$ \\
\hline 90-genesis lat & $\mathbf{1 . 8 9}$ & $\mathbf{1 . 0 0}$ & $\mathbf{2 . 9 9}$ & 0.14 \\
vorticity & $\mathbf{0 . 8 0}$ & -0.01 & $\mathbf{3 . 5 0}$ & $\mathbf{- 0 . 7 3}$ \\
speed & $\mathbf{5 . 8 3}$ & $\mathbf{2 . 4 6}$ & $\mathbf{5 . 6 9}$ & $\mathbf{2 . 5 9}$ \\
vorticity:speed & $\mathbf{- 0 . 7 8}$ & -0.16 & -0.34 & -0.15 \\
vorticity:90-genesis lat & $\mathbf{- 0 . 7 5}$ & $\mathbf{- 0 . 3 7}$ & $\mathbf{- 0 . 8 8}$ & $\mathbf{- 1 . 4 0}$ \\
speed:90-genesis lat & -0.43 & $4.4 \times 10^{-3}$ & -0.67 & 0.32 \\
\hline
\end{tabular}



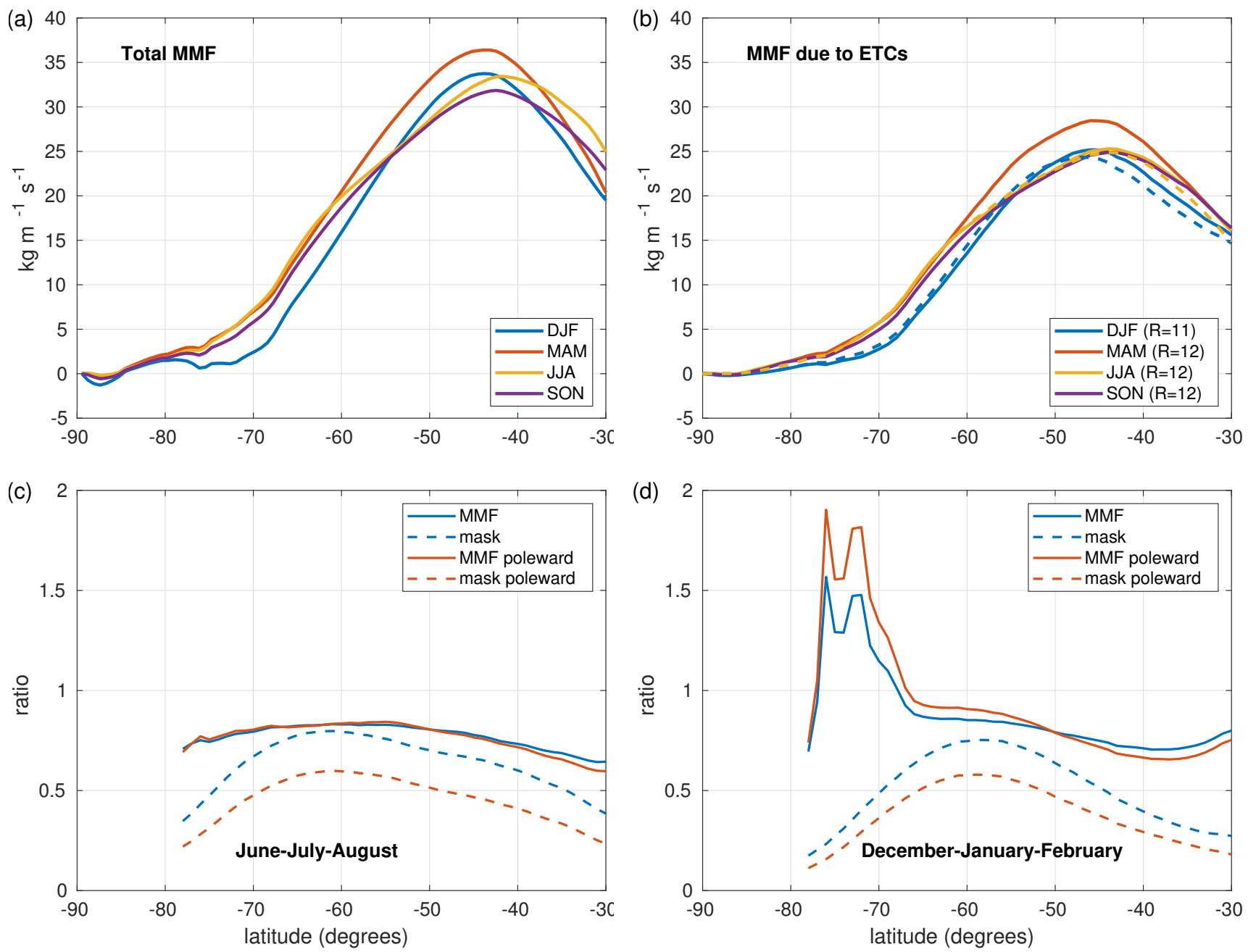

Figure 3. Zonally averaged (a) total meridional moisture flux, $\overline{M M F_{\text {TоT }}}$, and (b) ETC-related meridional moisture flux, $\overline{M M F_{E T C}}$, assuming a radius of 12 degrees in all seasons except DJF where 11 degrees is used, for DJF (red), MAM (orange), JJA (yellow) and SON (purple). Solid lines in (b) show meridional moisture flux due to all ETCs, dashed lines show meridional moisture flux due to poleward moving ETCs. (c) and (d) shows the ratio of ETC MMF to total MMF (solid lines) and the zonal mean occurrence of ETC masks at each latitude (dashed lines) for JJA and DJF respectively. Blues lines show ratios when all ETCs are considered and orange lines show ratios when only poleward moving ETCs are considered. 

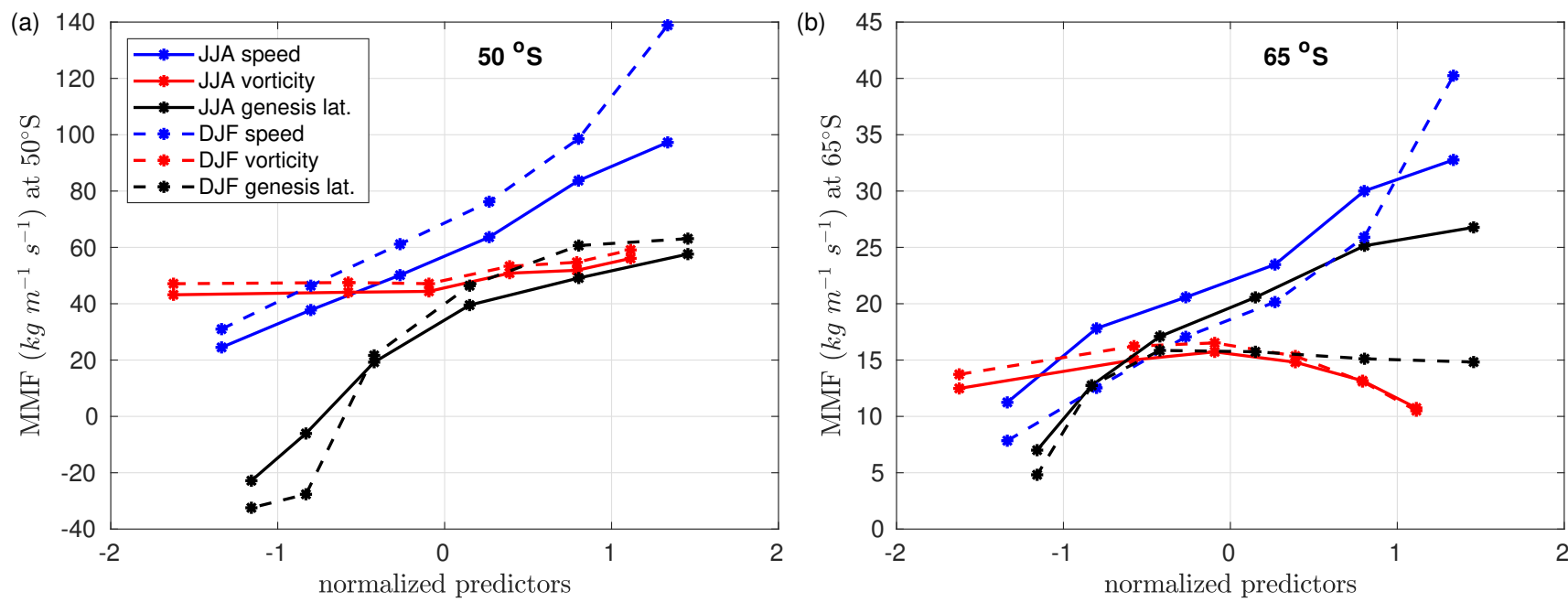

Figure 4. Relationship between ETC characteristics and zonally averaged ETC-related MMF per ETC mask, $\overline{\left|M M F_{E T C}\right|}$ at (a) $50^{\circ} \mathrm{S}$ and (b) $65^{\circ} \mathrm{S}$ for JJA (solid lines) and DJF (dashed lines). Predictor variables are centered on their mean and normalized by their standard deviation. The ETC characteristics are poleward propagation velocity (blue), maximum cyclonic vorticity (red), and genesis latitude (black). Genesis latitude is represented by 90 - genesis latitude (distance from south pole). Only poleward moving ETCs are included. Slope coefficients are shown in Table 1. Note the different y-axis between the two panels. 
(a)
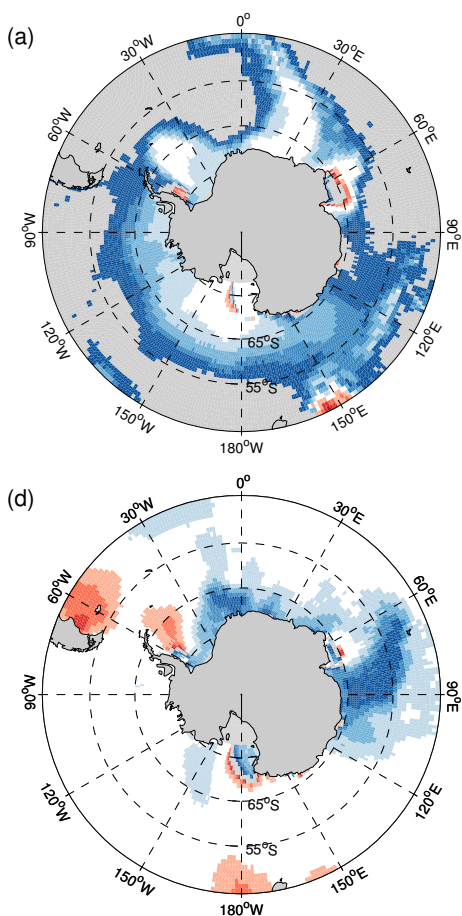

(g)

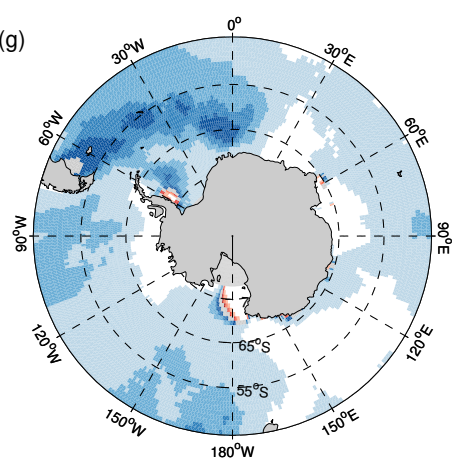

(b)

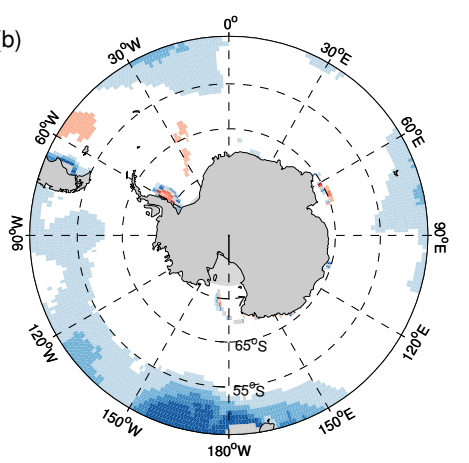

(e)
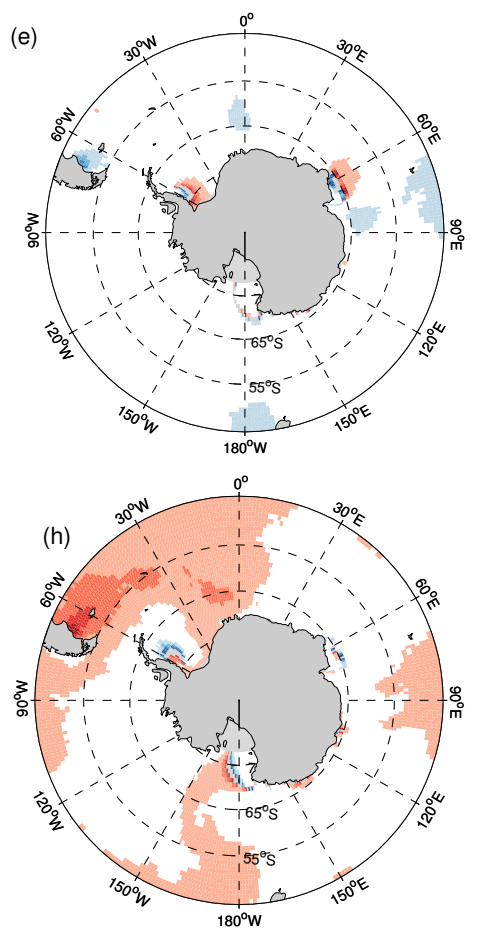

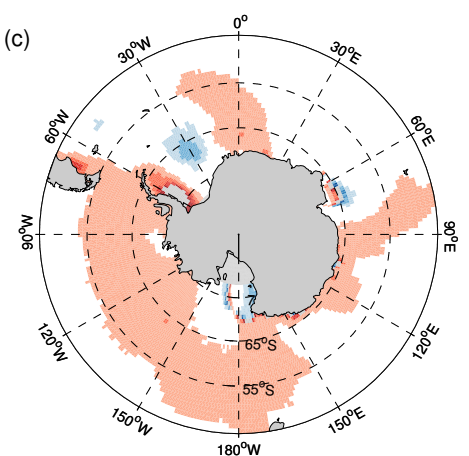

(c)

(f)

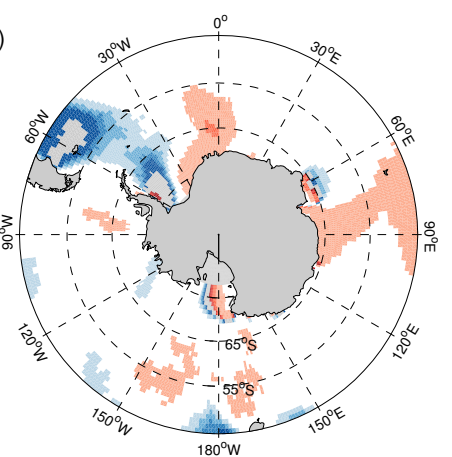

(i)

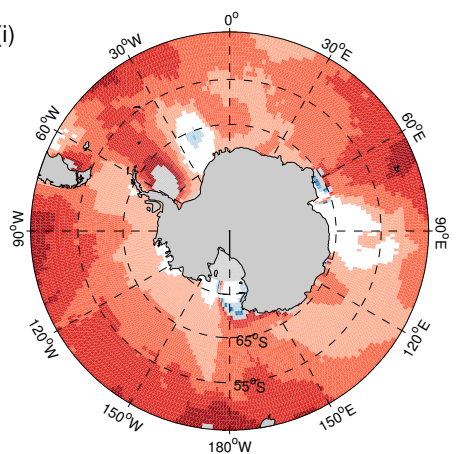

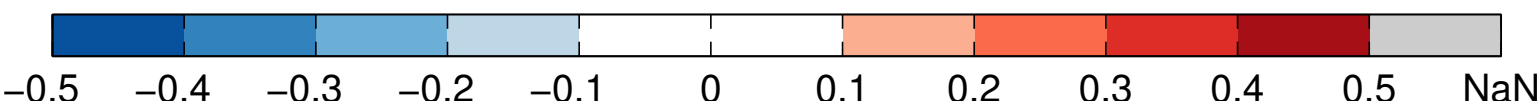

Figure 5. JJA: $\log _{10}$ of the ratio between MMF per ETC for a given bin, $i,\left|M M F_{E T C}\right|^{i}$, and the MMF per ETC for all ETCs, $\left|M M F_{E T C}\right|$. Top row: different genesis latitudes. (a) south of $62.5^{\circ} \mathrm{S}$, (b) $45-62.5^{\circ} \mathrm{S}$ and (c) north of $45^{\circ} \mathrm{S}$. Middle row: different maximum $850-\mathrm{hPa}$ relative vorticity. (d) less than $6.5 \times 10^{-5} \mathrm{~s}^{-1}$, (e) $6.5 \times 10^{-5}-9.5 \times 10^{-5} \mathrm{~s}^{-1}$, (f) greater than $9.5 \times 10^{-5}$ $\mathrm{s}^{-1}$. Bottom row: different meridional speed. (g) less than 4 degrees latitude per day, (h) 4 8 degrees latitude per day, (i) greater than 8 degrees latitude per day. Only poleward moving ETCs are considered. Grey areas are where the ratio $\left(\left|M M F_{E T C}\right|^{i} /\left|M M F_{E T C}\right|\right)$ is negative or over Antarctica. 

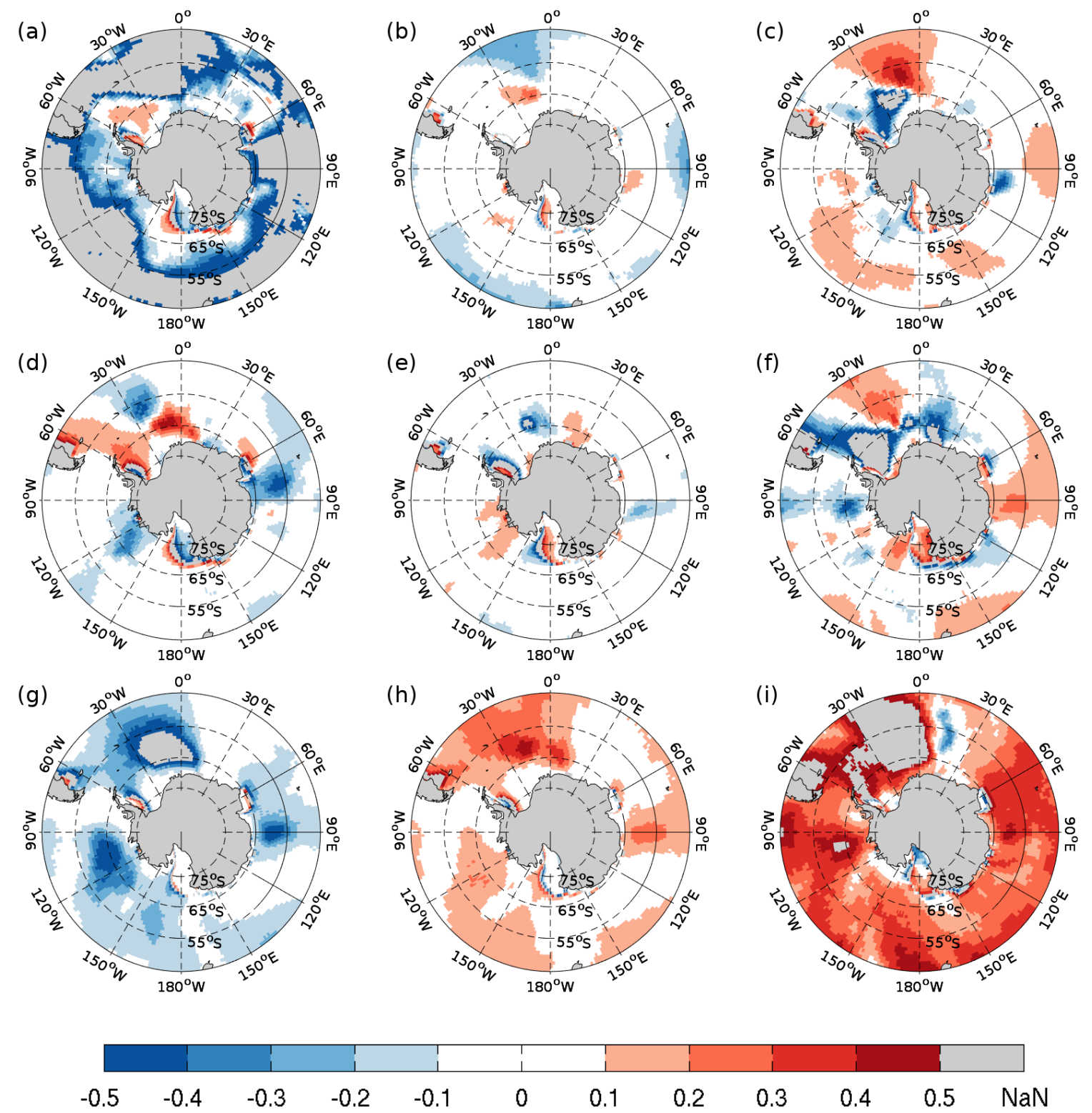

Figure 6. DJF: $\log _{10}$ of the ratio between MMF per ETC for a given bin, $i,\left|M M F_{E T C}\right|^{i}$, and the MMF per ETC for all ETCs, $\left|M M F_{E T C}\right|$. Top row: different genesis latitudes. (a) south of $62.5^{\circ} \mathrm{S}$, (b) $45-62.5^{\circ} \mathrm{S}$ and (c) north of $45^{\circ} \mathrm{S}$. Middle row: different maximum $850-\mathrm{hPa}$ relative vorticity. (d) less than $6.5 \times 10^{-5} \mathrm{~s}^{-1}$, (e) $6.5 \times 10^{-5}-9.5 \times 10^{-5} \mathrm{~s}^{-1}$, (f) greater than $9.5 \times 10^{-5}$

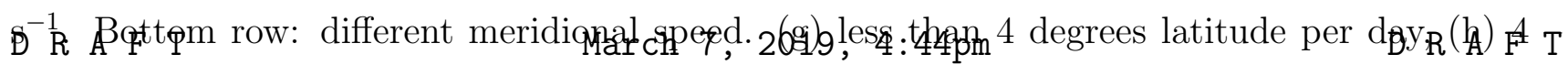
8 degrees latitude per day, (i) greater than 8 degrees latitude per day. Only poleward moving ETCs are considered. Grey areas are where the ratio $\left(\left|M M F_{E T C}\right|^{i} /\left|M M F_{E T C}\right|\right)$ is negative or over Antarctica. 

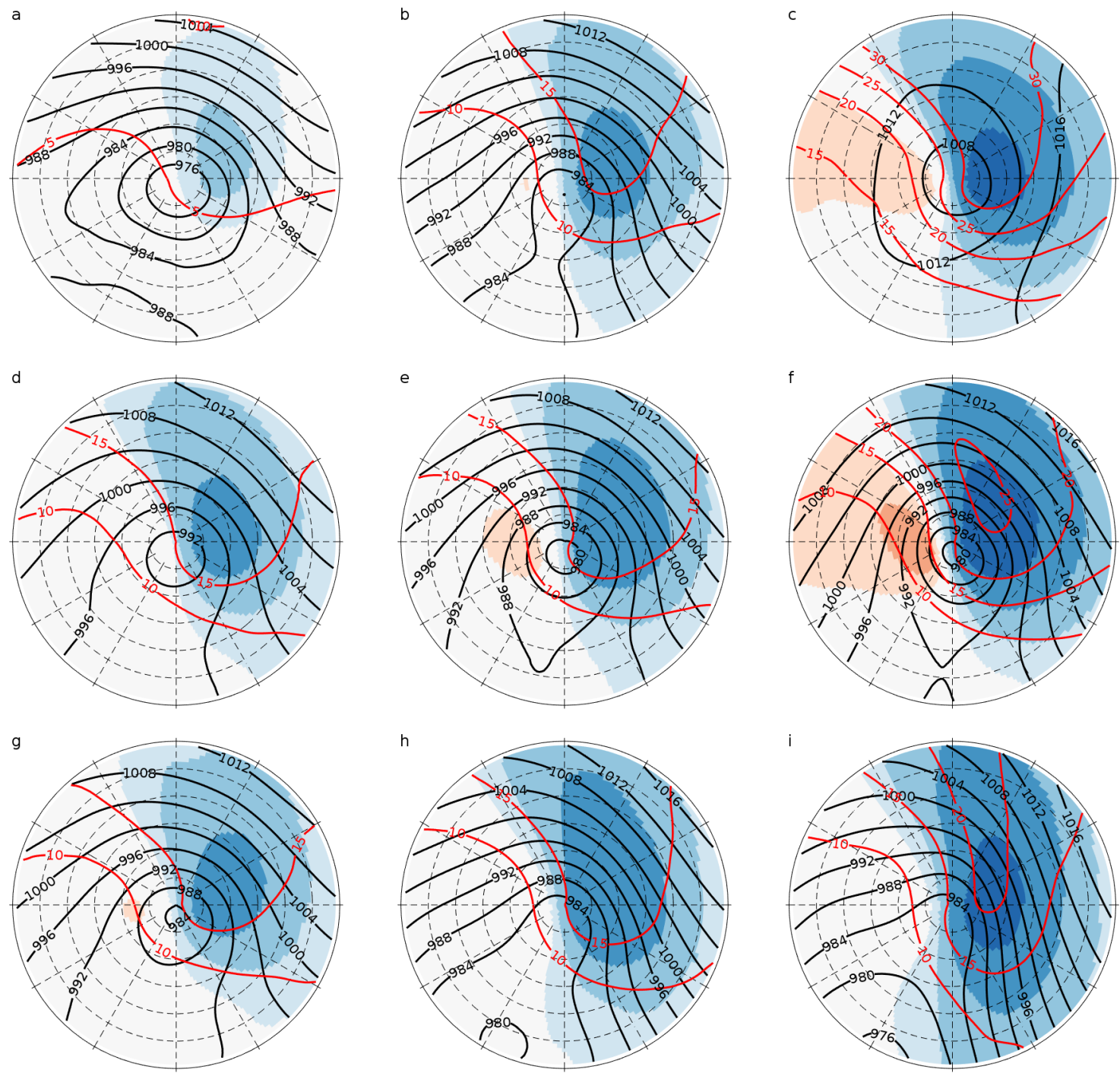

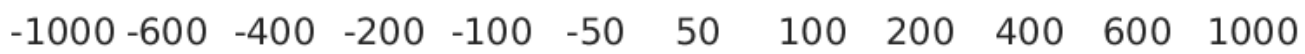

Figure 7. Composites of the meridional moisture flux (shading, $\mathrm{kg} \mathrm{m}^{-1} \mathrm{~s}^{-1}$ ), MSLP (black contours, hPa) and TCWV (red contours, $\mathrm{kg} \mathrm{m}^{-2}$ ) for ETCs occurring in JJA 24 hours before

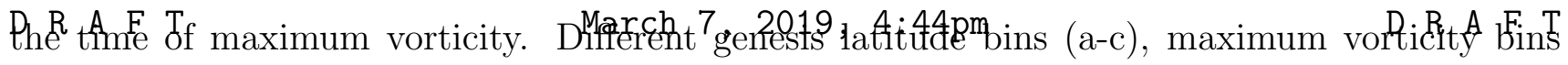
(d-f) and speed bins (g-i). Left column shows bin 2, center column bin 4 and right column bin 6. See Table 1 for bin definitions. 
a

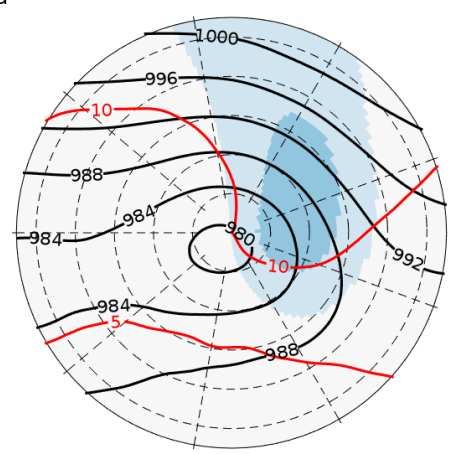

d

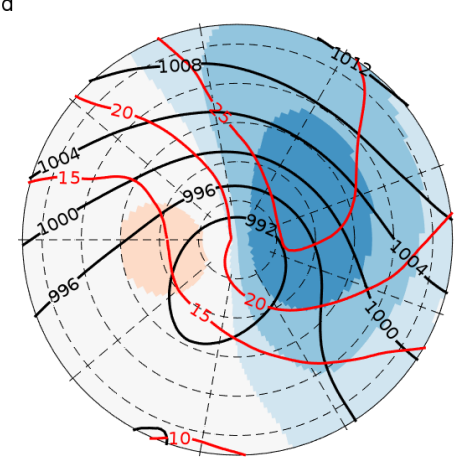

g

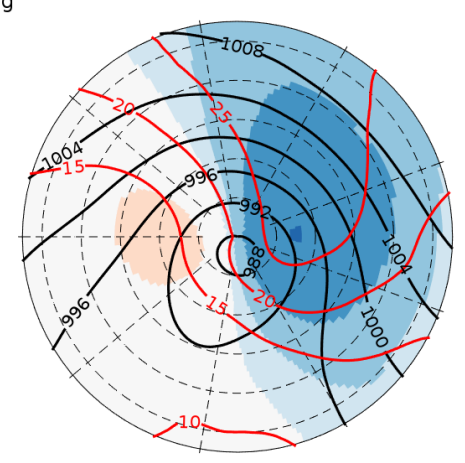

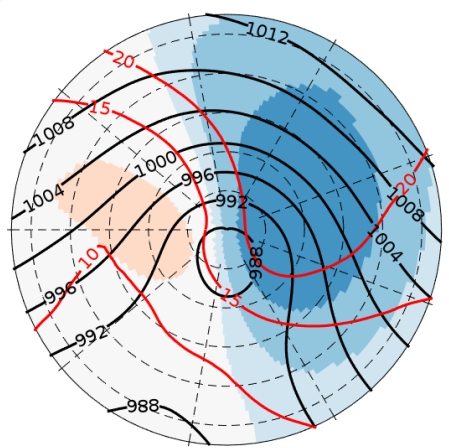
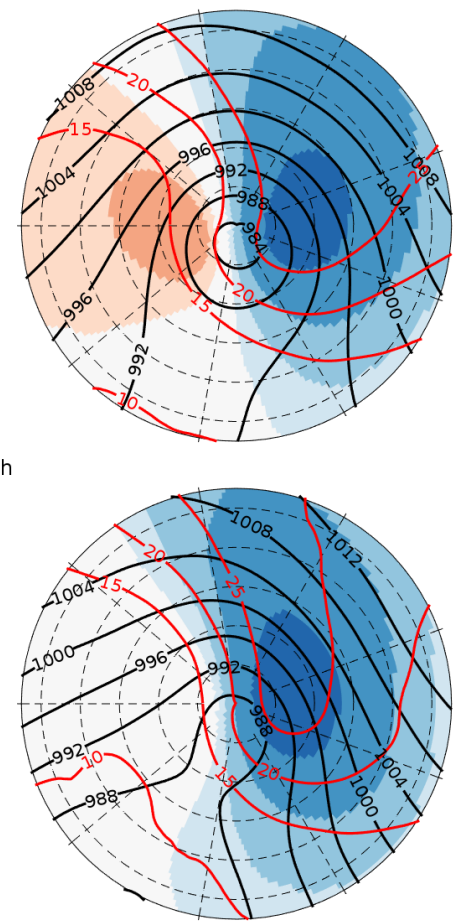

c
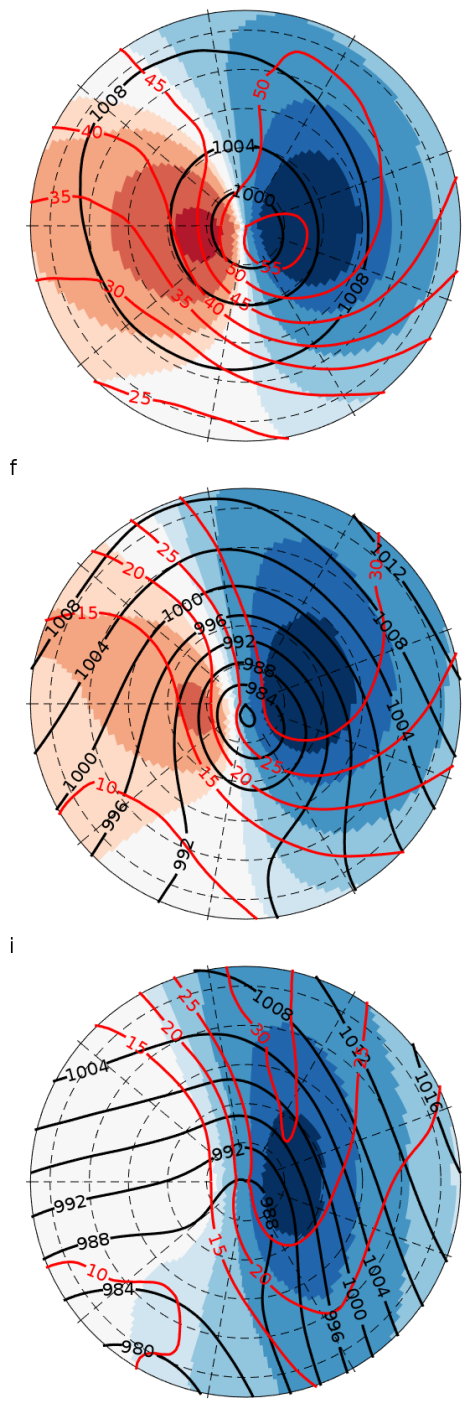

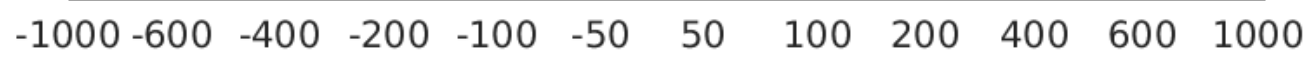

Figure 8. Same as Figure 7 except for DJF and with a radius of 11 degrees. 

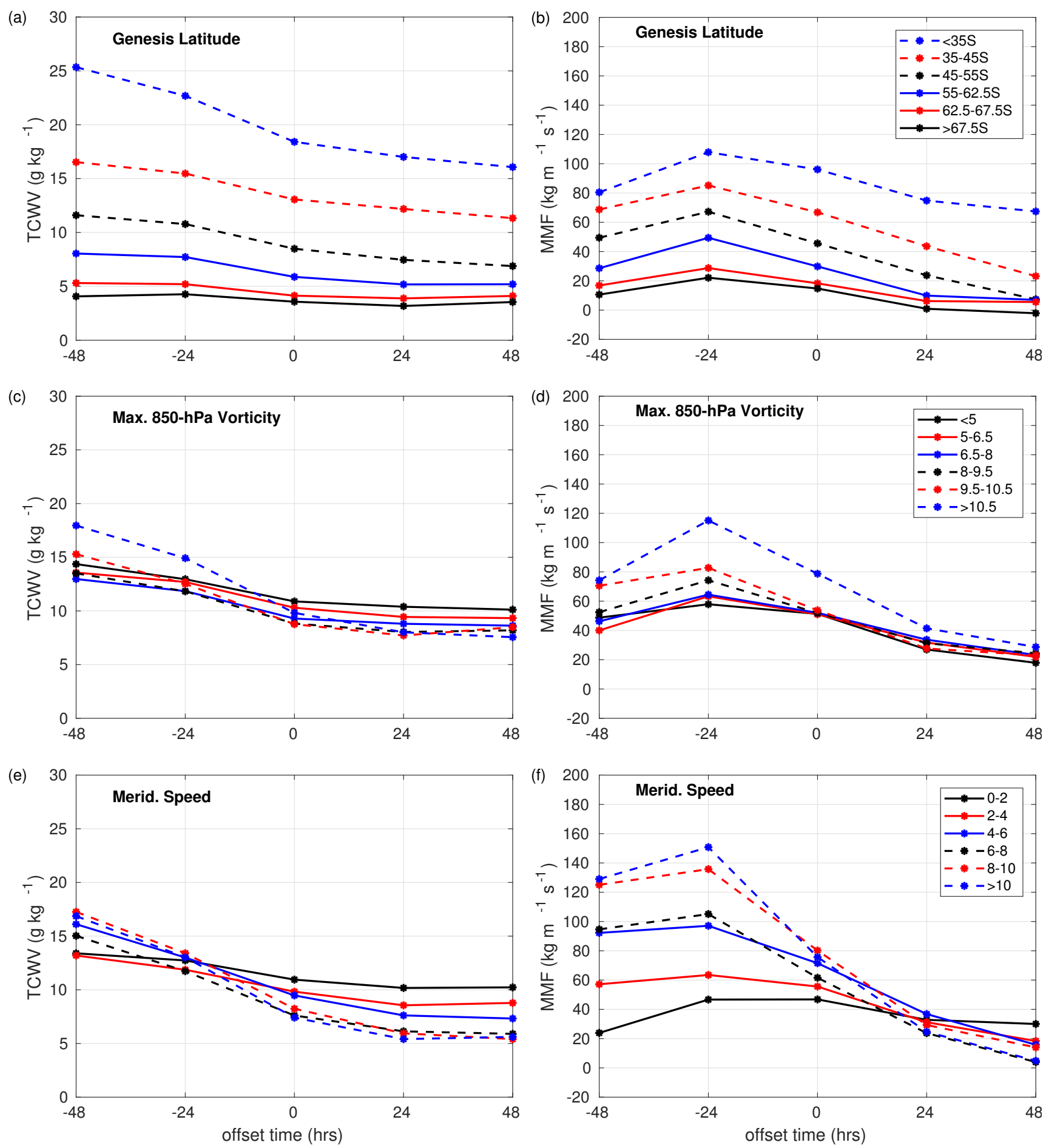

Figure 9. Mean total column water vapor (TCWV) and net vertically integrated meridional moisture flux (MMF) per unit area for cyclones in JJA as a function of time for different genesis latitude bins (a, b), different maximum vorticity bins (c,d) and different speed bins (e,f). Black solid lines: bin 1, red solid lines: bin 2, blue solid lines: bin3, black dashed lines: bin 4, red

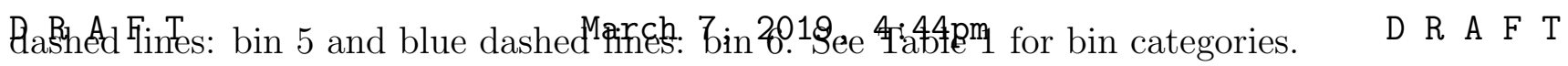



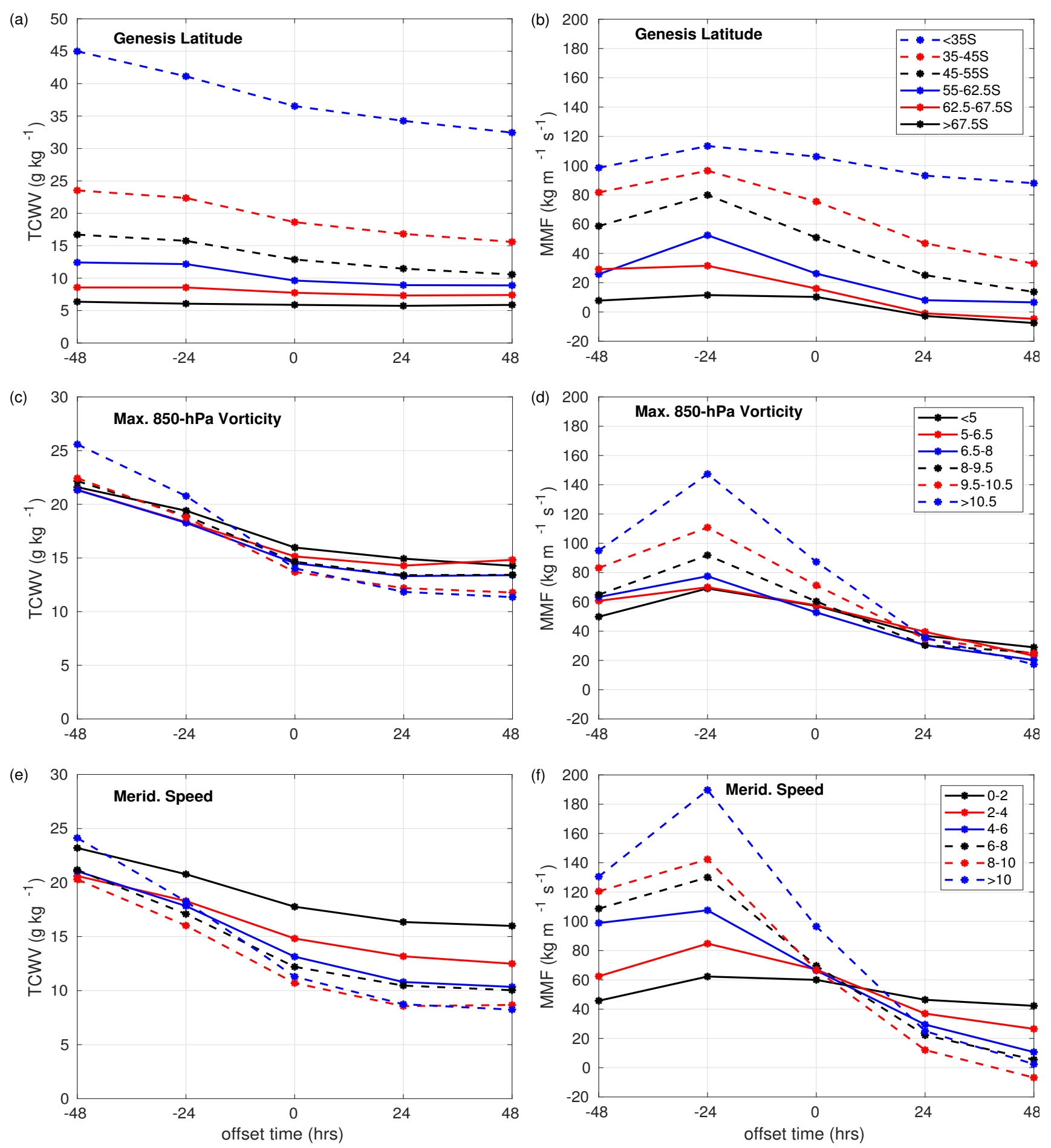

Figure 10. Storm averaged total column water vapor (TCWV) and vertically integrated meridional moisture flux (MMF) for cyclones in DJF (radius equal to 11 degrees) as a function of time for different genesis latitude bins (a, b), different maximum vorticity bins (c,d) and different speed bins (e,f). Black solid lines: bin 1, red solid lines: bin 2, blue solid lines: bin3,

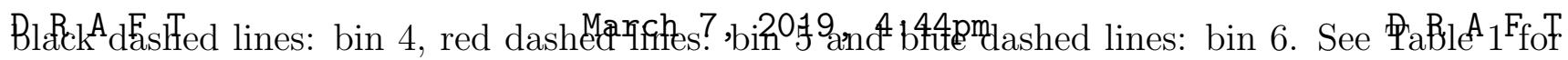
bin categories. 
Table 4. Regression coefficients for TCVW and MMF from composite cyclones in JJA and DJF. Values in bold are statistically significant at the $99 \%$ level.

\begin{tabular}{c|cccccc}
\hline Variable & \multicolumn{3}{|c}{ TCWV } & \multicolumn{3}{c}{ MMF } \\
\hline offset time (hr) & genesis lat & vorticity & \multicolumn{2}{c}{ speed genesis lat } & vorticity & speed \\
& \multicolumn{7}{|c}{ JJA } \\
\hline-48 & $\mathbf{7 . 9 4}$ & 1.34 & $\mathbf{1 . 5 2}$ & $\mathbf{2 8 . 0 7}$ & $\mathbf{1 1 . 8 4}$ & $\mathbf{3 9 . 3 0}$ \\
-24 & $\mathbf{6 . 9 5}$ & 0.54 & 0.25 & $\mathbf{3 3 . 0 2}$ & $\mathbf{1 9 . 7 3}$ & $\mathbf{3 9 . 8 5}$ \\
0 & $\mathbf{5 . 7 2}$ & -0.49 & $\mathbf{- 1 . 3 1}$ & $\mathbf{3 1 . 2 2}$ & 8.58 & $\mathbf{1 1 . 1 8}$ \\
24 & $\mathbf{5 . 3 3}$ & $\mathbf{- 0 . 9 1}$ & $\mathbf{- 1 . 7 8}$ & $\mathbf{2 7 . 6 4}$ & 3.57 & -3.17 \\
48 & $\mathbf{4 . 7 3}$ & $\mathbf{- 0 . 8 6}$ & $\mathbf{- 1 . 8 6}$ & $\mathbf{2 3 . 1 6}$ & $\mathbf{3 . 2 6}$ & $\mathbf{- 8 . 1 6}$ \\
\hline \multicolumn{7}{|c}{ DJF } \\
-48 & $\mathbf{1 3 . 9 9}$ & $\mathbf{1 . 3 2}$ & -0.54 & $\mathbf{3 4 . 7 6}$ & $\mathbf{1 5 . 0 0}$ & $\mathbf{3 2 . 4 8}$ \\
-24 & $\mathbf{1 2 . 6 6}$ & 0.50 & $\mathbf{- 1 . 0 7}$ & $\mathbf{3 8 . 5 9}$ & $\mathbf{2 5 . 5 2}$ & $\mathbf{4 4 . 4 8}$ \\
0 & $\mathbf{1 1 . 0 6}$ & $\mathbf{- 0 . 7 2}$ & $\mathbf{- 1 . 0 1}$ & $\mathbf{3 7 . 3 2}$ & $\mathbf{9 . 1 9}$ & 9.88 \\
24 & $\mathbf{1 0 . 2 5}$ & $\mathbf{- 1 . 1 4}$ & $\mathbf{- 0 . 9 8}$ & $\mathbf{3 5 . 5 4}$ & -1.32 & $\mathbf{- 1 0 . 0 9}$ \\
48 & $\mathbf{9 . 4 6}$ & $\mathbf{- 1 . 2 4}$ & $\mathbf{- 0 . 9 4}$ & $\mathbf{3 3 . 3 2}$ & -2.70 & $\mathbf{1 6 . 2 5}$
\end{tabular}

